\title{
Di-Huang-Yi-Zhi herbal formula attenuates amyloid- $\beta$-induced neurotoxicity in PC12 cells
}

\author{
HONG-MEI AN ${ }^{1 *}$, CHEN LIN $^{1 *}$, CHAO GU $^{1}$, JIN-JUN CHEN $^{2}$, WEN-XIAN SUN ${ }^{1}$, \\ MIAO JIN $^{1}$, TIAN-LI ZHANG ${ }^{1}$, MING-FENG QIU ${ }^{3}$ and BING HU ${ }^{4}$
}

\begin{abstract}
${ }^{1}$ Department of Neurology, Longhua Hospital, Shanghai University of Traditional Chinese Medicine, Shanghai 200032;
${ }^{2}$ Department of Plastic and Reconstructive Surgery, Shanghai Key Laboratory of Tissue Engineering, The Ninth People's Hospital, School of Medicine, Shanghai Jiaotong University, Shanghai 200011; ${ }^{3}$ School of Pharmacy, Shanghai Jiao Tong University, Shanghai 200240; ${ }^{4}$ Department of Oncology and Institute of Traditional Chinese Medicine in Oncology, Longhua Hospital, Shanghai University of Traditional Chinese Medicine, Shanghai 200032, P.R. China
\end{abstract}

Received January 17, 2016; Accepted January 13, 2017

DOI: $10.3892 /$ etm.2017.4368

\begin{abstract}
Traditional Chinese medicine can be used for Alzheimer's disease management, such as the modern herbal formula Di-Huang-Yi-Zhi (DHYZ). In the present study, neuronal differentiated PC12 cells were used as a model to evaluate the effects of DHYZ against amyloid- $\beta$ peptide 25-35 (A $\left.\beta_{25-35}\right)$ induced neurotoxicity, particularly regarding cell proliferation, apoptosis and related events. Following treatment with DHYZ, cell viability, cell membrane damage, apoptosis, mitochondrial membrane potential, cytochrome c release, caspase-3 activity and levels of reactive oxygen species in PC12 cells were detected. The results demonstrated that pretreatment with DHYZ significantly protected PC12 cells from $A \beta_{25-35}$-induced proliferation inhibition, lactate dehydrogenase release and apoptosis, as well as upregulating mitochondrial membrane potential and downregulating cytochrome $c$ release and caspase-3 activation. DHYZ also inhibited the $A \beta_{25-35}$-induced reactive oxygen species generation in $\mathrm{PC} 12$ cells. These observations suggest that $\mathrm{DHYZ}$ protected $\mathrm{PC} 12$ cells from the $\mathrm{A} \beta$-induced neurotoxicity.
\end{abstract}

Correspondence to: Dr Bing Hu, Department of Oncology and Institute of Traditional Chinese Medicine in Oncology, Longhua Hospital, Shanghai University of Traditional Chinese Medicine, No. 12 Building, 725 South Wanping Road, Shanghai 200032, P.R. China

E-mail: beearhu@hotmail.com

Dr Ming-Feng Qiu, School of Pharmacy, Shanghai Jiao Tong University, No. 7 Building, 800 Dongchuan Road, Shanghai 200240, P.R. China

E-mail:mfqiu@sjtu.edu.cn

*Contributed equally

Key words: amyloid- $\beta$, PC12 cells, Di-Huang-Yi-Zhi, apoptosis, mitochondria, reactive oxygen species

\section{Introduction}

Alzheimer's disease (AD), the most frequent cause of dementia, is an age-associated progressive neurodegenerative disorder characterized by memory loss and cognitive decline. Amyloid- $\beta(A \beta)$-induced neurotoxicity and oxidative stress contribute to $\mathrm{AD}$ pathogenesis $(1,2)$. Therefore, $\mathrm{A} \beta$-induced neuronal cell damage is widely used as a model to investigate neuroprotective agents. Currently approved drugs, including donepezil, galantamine, rivastigmine and memantine, only demonstrate marginal therapeutic benefits for AD (3). Thus, there is an urgent requirement to develop novel approaches for $\mathrm{AD}$ treatment.

Traditional Chinese medicine (TCM) formulas can be a valuable medical and pharmaceutical resource for AD management. TCM herbal treatments, including Tiao-Xin-Fang, Bu-Shen-Fang and Yi-zhi-Fang-Dai granules, have demonstrated efficacy in improving cognitive and brain function, and in ameliorating clinical symptoms in AD patients $(4,5)$. Combined Chinese and Western medicine has shown better efficacy compared with modern drug therapy alone in AD treatment (6). Based on the TCM principles and studies in Chinese herbal pharmacology, previous studies by our group established a Di-Huang-Yi-Zhi (DHYZ) formula, mainly comprised of the herbs Shu-Di, Dan-Shen, Yi-Zhi-Ren, Fu-Shen and Shi-Chang-Pu (Chinese patent no. ZL2008102047153.3), for the treatment of $\operatorname{AD}(7,8)$.

DHYZ herbal extracts have been demonstrated to be effective in improving the learning and memory abilities in rats with dementia induced by $A \beta$ that is accompanied by decreased choline acetyltransferase activities and increased acetylcholinesterase activities (7). DHYZ also improves the daily life and cognitive abilities, and relieves clinical symptoms, while it has shown enhanced efficacy when combined with donepezil in $A D$ patients (8). Since $A \beta$ mediated neurotoxicity is closely related to the pathogenesis of $\mathrm{AD}$, the current study used neuronal differentiated $\mathrm{PC} 12$ cells treated with $\mathrm{A} \beta$ as a model of $A \beta$ neurotoxicity to evaluate the potential neuroprotective effects of DHYZ herbs. 


\section{Materials and methods}

Chemicals and reagents. $\mathrm{A} \beta$ protein fragment 25-35 (A $\beta_{25-35}$; cat. no. A4559-1MG) was obtained from Sigma-Aldrich (Merck KGaA, Darmstadt, Germany). Recombinant rat nerve growth factor (NGF) and Rat/Mouse Cytochrome $c$ (Cyt-C) ELISA kits (cat. nos. 7815-NG and MCTC0, respectively) were obtained from R\&D Systems (Minneapolis, MN, USA). A Cell Counting kit-8 (CCK-8; cat. no. CK04) was purchased from Dojindo (Kumamoto, Japan) and a Cell Death Detection ELISA ${ }^{\text {Plus }}$ kit (cat. no. 11774425001) was purchased from Roche Applied Sciences (Basel, Switzerland). A lactate dehydrogenase (LDH) Cytotoxicity Assay kit was obtained from Cayman Chemical (cat. no. 601170; Ann Arbor, MI, USA). A BCA Protein assay kit (cat. no. P0010S), mitochondrial membrane potential assay kit (cat. no. C2006), caspase-3 activity assay kit (cat. no. C1116), cytoplasmic protein extraction kit (cat. no. P0028) and 2',7'-dichlorofluorescin diacetate (DCFH-DA; cat. no. S0033) were provided by Beyotime Institute of Biotechnology (Jiangsu, China).

Preparation of herbal extract. The main herbs in the DHYZ formula are processed root of Rehmannia glutinosa (Gdertn) Libosch. (Shu-Di), the root of Salvia miltiorrhiza Bge (Dan-Shen), the fruits of Alpinia oxyphylla Miq. (Yi-Zhi-Ren), Poria with hostwood (Fu-Shen) and the root of Acorus tatarinowii Schott (Shi-Chang-Pu) (Chinese patent no. ZL2008102047153.3). Extraction and quality control of DHYZ was performed as previously described (9-11). Briefly, the herbs were identified by thin layer chromatography, and salvianolic acid B was used as an indicator for quality control. Herbs were extracted first with a 10 -fold volume of boiling distilled water for $1 \mathrm{~h}$, then with a 6-fold volume of boiling distilled water for $1 \mathrm{~h}$. Two aqueous extracts of the herbs were combined and precipitated with 50\% ethanol for $24 \mathrm{~h}$, centrifuged at 5,000 $\mathrm{x} g$ for $10 \mathrm{~min}$ at $4^{\circ} \mathrm{C}$, then evaporated in vacuum conditions for $12 \mathrm{~h}$ at $60^{\circ} \mathrm{C}$. Subsequently, the ethanol extracts were dissolved in RPMI 1640 medium (Thermo Fisher Scientific, Inc.), sequentially passed through 0.45 and $0.22 \mu \mathrm{m}$ filters for sterilization, and stored at $4^{\circ} \mathrm{C}$ until further use.

A $\beta$ preparation. $\mathrm{A} \beta_{25-35}$ aggregation was prepared as described previously (12). Briefly, lyophilized $A \beta_{25-35}$ was dissolved in RPMI 1640 medium and incubated at $37^{\circ} \mathrm{C}$ with constant oscillation for 3 days in order to induce aggregation. The aggregated $\mathrm{A} \beta_{25-35}$ was then diluted to $100 \mu \mathrm{g} / \mathrm{ml}(100 \mu \mathrm{M})$ and stored at $-20^{\circ} \mathrm{C}$ until required.

Cell culture. PC12 cells were obtained from the Cell Bank of Type Culture Collection of Chinese Academy of Sciences (Shanghai, China). PC12 cells were grown in RPMI 1640 medium with $10 \%$ horse serum (cat. no. 16050122), 5\% fetal bovine serum (cat. no. 10099-141) and 1\% Pen-Strep (cat. no. 15140122; all from Thermo Fisher Scientific, Inc., Waltham, MA, USA), and maintained at $37^{\circ} \mathrm{C}$ in a humidified incubator in a $5 \% \mathrm{CO}_{2}$ atmosphere for 2-3 d. PC12 cells were treated with NGF $(50 \mathrm{ng} / \mathrm{ml})$ for 2 days at $37^{\circ} \mathrm{C}$ to induce neuronal differentiation, and subsequently examined by a microscope $(13,14)$. Differentiated PC12 cells were used in all experiments.
Cell viability assay. Differentiated $\mathrm{PC} 12$ cells were seeded into 96-well plate $\left(8 \times 10^{3}\right.$ cells/well) and grown in complete RPMI 1640 medium for $24 \mathrm{~h}$ at $37^{\circ} \mathrm{C}$. Cells were then pretreated with various doses of DHYZ (10, 20 and $40 \mu \mathrm{g} / \mathrm{ml})$ for $1 \mathrm{~h}$ at $37^{\circ} \mathrm{C}$, followed by $20 \mu \mathrm{M}$ aggregated $\mathrm{A} \beta_{25-35}$ treatment for $24 \mathrm{~h}$ at $37^{\circ} \mathrm{C}$. Cells treated with the same volume of RPMI 1640 medium alone were used as a control. At the end of the treatment, cell viability was evaluated by a CCK- 8 assay according to the manufacturer's instructions. Cell viability rate was calculated on the basis of the optical density (OD), as follows: Cell viability $(\%)=($ Experimental OD value/control OD value) $\mathrm{x} 100 \%$.

$L D H$ release assay. Differentiated PC12 cells were seeded and treated as described for the cell viability assay. At the end of the treatment, $A \beta_{25-35}$-induced cytotoxicity was evaluated by an LDH release assay, according to the manufacturer's instructions. The results are expressed as the fold change compared with the control group.

Quantification of cell apoptosis. Differentiated PC12 cells were seeded and treated as described for the cell viability assay. At the end of the treatment, PC12 cells were collected for quantification of DNA fragmentation using the Cell Death Detection ELISA ${ }^{\text {Plus }}$ kit, according to the manufacturer's protocol. Results are expressed as the fold change compared with the non-treated control.

Measurement of mitochondrial membrane potential (MMP). Differentiated PC12 cells were seeded into 24-well plate ( $4 \times 10^{4}$ cells/well) and grown in complete RPMI 1640 medium for $24 \mathrm{~h}$ at $37^{\circ} \mathrm{C}$. Cells were then pre-incubated with or without $\operatorname{DHYZ}(10,20$ and $40 \mu \mathrm{g} / \mathrm{ml})$ for $1 \mathrm{~h}$ at $37^{\circ} \mathrm{C}$, followed by exposure to $20 \mu \mathrm{M}$ aggregated $\mathrm{A} \beta_{25-35}$ for $24 \mathrm{~h}$ at $37^{\circ} \mathrm{C}$. Cells treated with with the same volume of RPMI 1640 medium alone were used as control. MMP changes were determined using the MMP assay kit, according to the manufacturer's protocol. The presence of JC-1 fluorescence was observed under a fluorescence microscope.

Cyt $-\mathrm{C}$ release assay. The release of Cyt- $\mathrm{C}$ from mitochondria into the cytosol was assessed by ELISA. Differentiated PC12 cells were seeded into 6 -well plate $\left(2 \times 10^{5}\right.$ cells/well) and grown in complete RPMI 1640 medium for $24 \mathrm{~h}$ at $37^{\circ} \mathrm{C}$. Cells were then pretreated with or without DHYZ (10, 20 and $40 \mu \mathrm{g} / \mathrm{ml}$ ) for $1 \mathrm{~h}$ at $37^{\circ} \mathrm{C}$, after which the cells were exposed to $20 \mu \mathrm{M}$ aggregated $\mathrm{A} \beta_{25-35}$ for $24 \mathrm{~h}$ at $37^{\circ} \mathrm{C}$. Cells treated with the same volume of RPMI 1640 medium alone were used as a control. After treatment, PC12 cells were collected and subjected to cytoplasmic protein extraction according to the manufacturer's protocol of the corresponding kit. Cytosolic Cyt-C was measured using the Rat/Mouse Cyt-C ELISA kit, according to the manufacturer's manual. The results are expressed as the fold change in comparison with the non-treated control.

Caspase-3 activity assay. Differentiated PC12 cells were seeded and treated as described for the Cyt-C release assay. Following treatment, $\mathrm{PC} 12$ cells were collected and subjected to caspase-3 activity detection by the cleavage of the specific chromogenic 
substrate according to the manufacturer's instructions of the kit. The results are expressed as the fold change in caspase- 3 activity in comparison with the non-treated control.

Measurement of reactive oxygen species (ROS) generation. Intracellular ROS production was detected by DCFH-DA staining. DCFH-DA is cleaved intracellularly by nonspecific esterases to form DCFH, which is further oxidized by ROS to form the fluorescent compound DCF. Differentiated PC12 cells were pre-incubated with or without DHYZ and exposed to aggregated $\mathrm{A} \beta_{25-35}$, as described for the aforementioned MPP assay. Cells were then stained with DCFH-DA at $37^{\circ} \mathrm{C}$ for $20 \mathrm{~min}$ in the dark. DCF fluorescence was quantified with a fluorescence microplate reader at an excitation wavelength of $488 \mathrm{~nm}$ and emission wavelength of $525 \mathrm{~nm}$. The results are expressed as the fold change compared with the non-treated control.

Statistical analysis. Results are expressed as the mean \pm standard deviation of at least two independent experiments, each conducted in triplicate. Differences between the control and treatment groups were analyzed by one-way analysis of variance. Differences were considered to be statistically significant at $\mathrm{P}<0.05$.

\section{Results}

Effect of DHYZ on the cell viability in A $\beta$-treated PC12 cells. A $\beta_{25-35}$-treated neuronal differentiated PC12 cells were used as a model to evaluate neuroprotective effects of DHYZ. The effects of DHYZ on cell viability in these cells were observed by CCK-8 assay. As shown in Fig. 1, A $\beta_{25-35}$ significantly inhibited PC12 cell growth compared with the control $(\mathrm{P}<0.01)$. By contrast, DHYZ treatment significantly increased the cell viability of $\mathrm{A} \beta_{25-35}$-treated $\mathrm{PC} 12$ cells in a dose-dependent manner relative to the $A \beta_{25-35}$ group $(\mathrm{P}<0.01)$, and the effects of $40 \mu \mathrm{g} / \mathrm{ml} \mathrm{DHYZ}$ were significantly greater than 10 and $20 \mu \mathrm{g} / \mathrm{ml} \mathrm{DHYZ}(\mathrm{P}<0.05)$.

Effect of DHYZ on LDH release in A $\beta$-treated PC12 cells. $\mathrm{LDH}$, a soluble cytosolic enzyme, is released from cells following the loss of cell membrane integrity due to cell death. $\mathrm{LDH}$ release was used as an indicator for $A \beta_{25-35}$-induced cytotoxicity. As shown in Fig. 2, A $\beta_{25-35}$ treatment significantly increased LDH leakage in PC12 cells compared with the non-treated control group $(\mathrm{P}<0.01)$. However, pretreatment with $10-40 \mu \mathrm{g} / \mathrm{ml}$ of DHYZ significantly decreased the $A \beta_{25-35}$-elicited LDH release in PC12 cells in a dose-dependent manner $(\mathrm{P}<0.05)$, and the effect of $40 \mu \mathrm{g} / \mathrm{ml}$ DHYZ in reducing LDH release was significantly greater than that observed for 10 and $20 \mu \mathrm{g} / \mathrm{ml}$ DHYZ $(\mathrm{P}<0.05)$.

Effect of DHYZ on A $\beta$-induced apoptosis in PC12 cells. The effect of DHYZ on cell death in A $\beta_{25-35}$-treated PC12 cells was measured by ELISA, which specifically detects cytoplasmic histone-associated DNA fragments (mono- and oligonucleosomes), which indicate apoptosis. The results indicated that $\mathrm{A} \beta_{25-35}$ significantly induced apoptosis in PC12 cells compared with the control group $(\mathrm{P}<0.01)$. However, pretreatment with $10-40 \mu \mathrm{g} / \mathrm{ml}$ DHYZ significantly protected PC12 cells

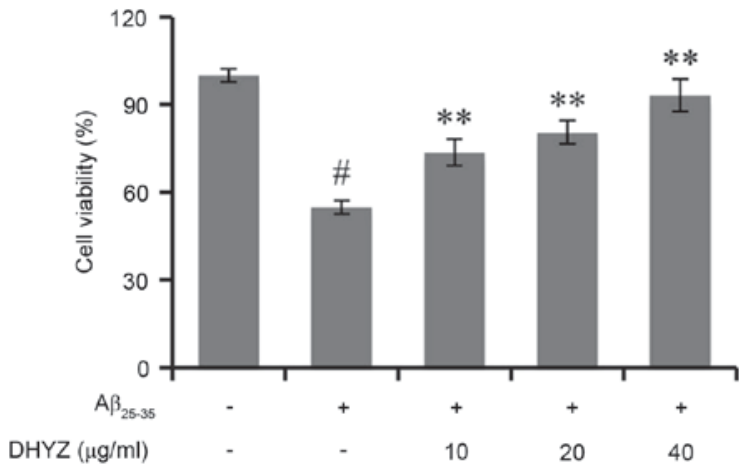

Figure 1. Effect of DHYZ on the cell viability in A $\beta$-treated PC12 cells. Differentiated PC12 cells were pretreated with different concentrations of DHYZ for $1 \mathrm{~h}$, followed by $\mathrm{A} \beta_{25-35}$ treatment for $24 \mathrm{~h}$. Cell viability was evaluated by CCK-8 assay. Data shown are representative of three independent experiments. ${ }^{\#} \mathrm{P}<0.01$, vs. non-treated group; ${ }^{* *} \mathrm{P}<0.01$ vs. $\mathrm{A} \beta_{25-35}$ group. DHYZ, Di-Huang-Yi-Zhi; A $\beta$, amyloid- $\beta$; CCK-8, cell counting kit-8.

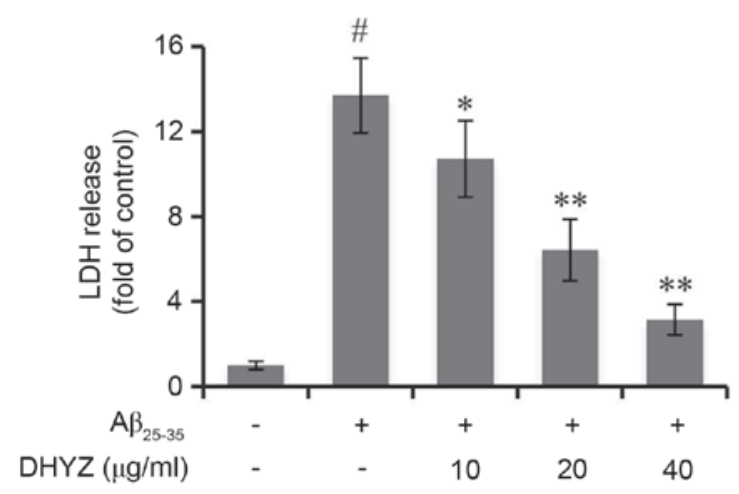

Figure 2. Effect of DHYZ on the LDH release in A $\beta$-treated PC12 cells. Differentiated PC12 cells were pretreated with different concentrations of DHYZ for $1 \mathrm{~h}$, followed by $\mathrm{A} \beta_{25-35}$ treatment for $24 \mathrm{~h}$. LDH release was determined by an LDH Cytotoxicity Assay kit, and is expressed as the fold of the control. Data are from three independent experiments. ${ }^{\#} \mathrm{P}<0.01$ vs. non-treated group; ${ }^{*} \mathrm{P}<0.05$ and ${ }^{* *} \mathrm{P}<0.01$ vs. $\mathrm{A} \beta_{25-35}$ group. DHYZ, Di-Huang-Yi-Zhi; $\mathrm{A} \beta$, amyloid- $\beta ; \mathrm{LDH}$, lactate dehydrogenase.

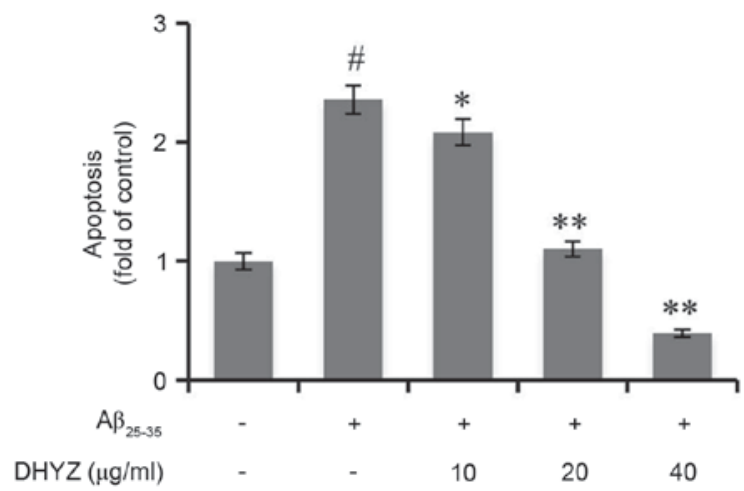

Figure 3. Effect of DHYZ on A $\beta$-induced apoptosis in PC12 cells. Differentiated PC12 cells were pretreated with different concentrations of DHYZ for $1 \mathrm{~h}$, followed by $A \beta_{25-35}$ treatment for $24 \mathrm{~h}$. Cell death was detected by ELISA. Results are expressed the as fold of the non-treated control, and were obtained from three separate experiments. ${ }^{*} \mathrm{P}<0.01$ vs. non-treated group; ${ }^{*} \mathrm{P}<0.05$ and ${ }^{* *} \mathrm{P}<0.01$, vs. $\mathrm{A} \beta_{25-35}$ group. DHYZ, Di-Huang-Yi-Zhi; $\mathrm{A} \beta$, amyloid- $\beta$.

from $\mathrm{A} \beta_{25-35}$-induced apoptosis in a dose-dependent manner $(\mathrm{P}<0.05)$, and the protective effects of $40 \mu \mathrm{g} / \mathrm{ml} \mathrm{DHYZ} \mathrm{were}$ 

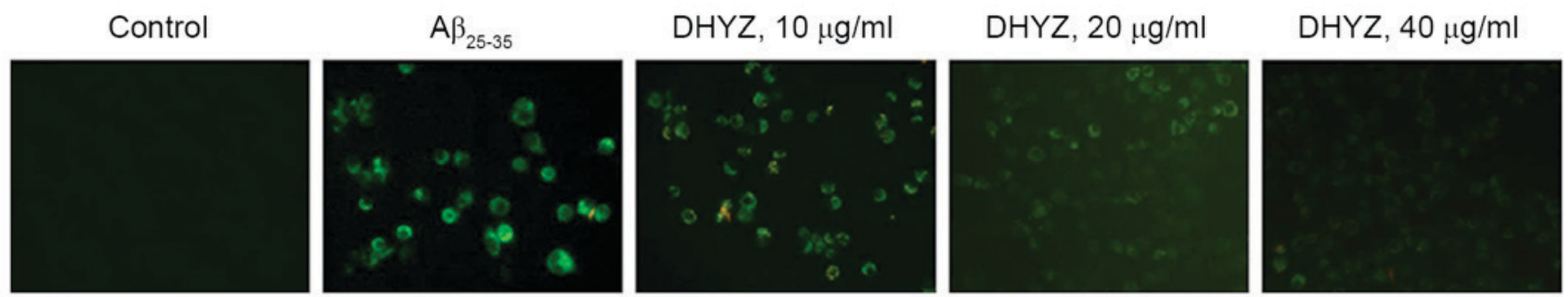

Figure 4. Effect of DHYZ on A $\beta$-induced MMP change in PC12 cells. Differentiated PC12 cells were pretreated with different concentrations of DHYZ for $1 \mathrm{~h}$, followed by $\mathrm{A} \beta_{25-35}$ treatment for $24 \mathrm{~h}$. MMP was detected by JC-1 staining, and observed under a fluorescence microscope (magnification, $\mathrm{x} 200$ ). DHYZ, Di-Huang-Yi-Zhi; $A \beta$, amyloid- $\beta$; MMP, mitochondrial membrane potential.

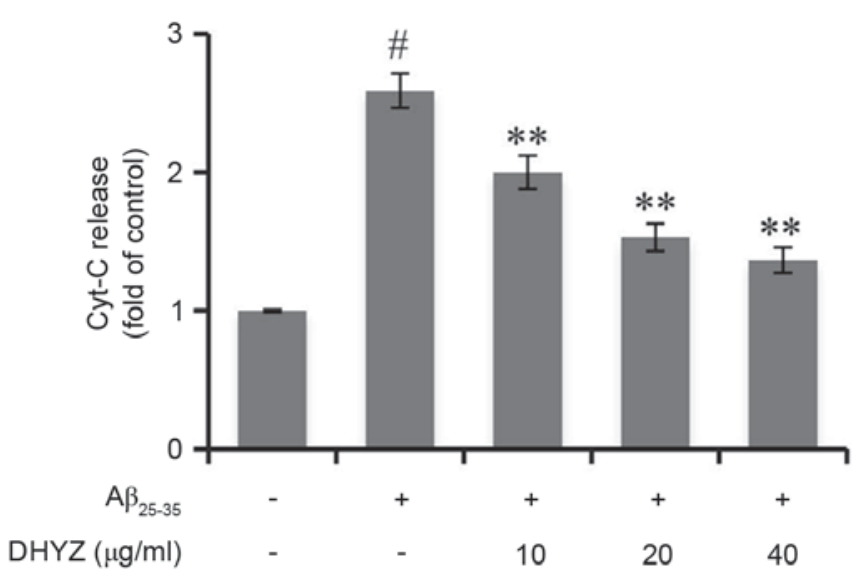

Figure 5. Effect of DHYZ on A $\beta$-elicited Cyt-C release in PC12 cells. Differentiated $\mathrm{PC} 12$ cells were pre-incubated with different concentrations of DHYZ for $1 \mathrm{~h}$, followed by $\mathrm{A} \beta_{25-35}$ treatment for $24 \mathrm{~h}$. Cyt-C concentration in the cytosol was determined by ELISA. Data are presented from three separate experiments. ${ }^{\#} \mathrm{P}<0.01$ vs. non-treated group; ${ }^{* *} \mathrm{P}<0.01$ vs. $\mathrm{A} \beta_{25-35}$ group. DHYZ, Di-Huang-Yi-Zhi; A $\beta$, amyloid- $\beta$; Cyt-C, cytochrome $c$.

significantly greater than those observed for 10 and $20 \mu \mathrm{g} / \mathrm{ml}$ DHYZ (P<0.01; Fig. 3).

Effects of DHYZ on A $\beta$-induced MMP change in PC12 cells. JC-1 was used to detect MMP as a parameter of mitochondrial function. JC-1 is a lipophilic cationic dye that remains in monomeric form and yields green fluorescence in apoptotic cells with low MMP. A $\beta_{25-35}$ treatment reduced the MMP in $\mathrm{PC} 12$ cells, as observed by the increased green fluorescence. By contrast, pre-incubation with $10-40 \mu \mathrm{g} / \mathrm{ml}$ of DHYZ countered the lowering MMP induced by $A \beta_{25-35}$ as indicated by reduced fluorescence (Fig. 4).

Effects of DHYZ on A $\beta$-induced Cyt-C release in PC12 cells. Mitochondrial dysfunction and subsequent $\mathrm{Cyt}-\mathrm{C}$ release are central events in apoptosis (15). In the present study, the Cyt-C concentration in the cytosol was measured by ELISA. PC12 cells treated with $A \beta_{25-35}$ showed an increase in cytosolic Cyt-C levels compared with the control levels $(\mathrm{P}<0.01)$. Pretreatment with $10-40 \mu \mathrm{g} / \mathrm{ml}$ DHYZ significantly attenuated $\mathrm{A} \beta_{25-35}$-induced Cyt-C release in a dose-dependent manner

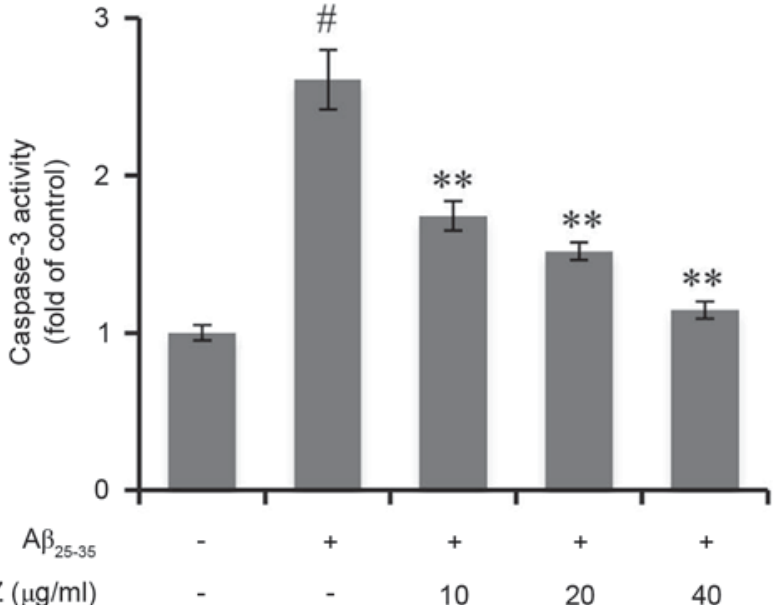

Figure 6. Effect of DHYZ on caspase-3 activity in $\mathrm{A} \beta_{25-35}$-treated PC12 cells. Differentiated PC12 cells were pretreated with different concentrations of DHYZ for $1 \mathrm{~h}$, followed by $\mathrm{A} \beta_{25-35}$ treatment for $24 \mathrm{~h}$. Caspase- 3 activity was detected using a kit, and is expressed as the fold of the control. Data shown are representative of three independent experiments. ${ }^{~} \mathrm{P}<0.01$ vs. non-treated group; ${ }^{* *} \mathrm{P}<0.01$ vs. $\mathrm{A} \beta_{25-35}$ group. DHYZ, Di-Huang-Yi-Zhi; $\mathrm{A} \beta$, amyloid- $\beta$.

$(\mathrm{P}<0.01)$, and the effect of $40 \mu \mathrm{g} / \mathrm{ml} \mathrm{DHYZ}$ in reducing Cyt-C release was significantly greater than that observed for $10 \mu \mathrm{g} / \mathrm{ml}$ DHYZ (P<0.01; Fig. 5).

Effect of DHYZ on caspase-3 activity in A $\beta$-treated PC12 cells. Cell apoptosis is executed by a caspase cascade. Caspase- 3 is the final executor of apoptosis, and its activation is a hallmark of apoptosis (16). As shown in Fig. 6, $\mathrm{A} \beta_{25-35}$ treatment activated caspase- 3 in PC12 cells when compared with the control group $(\mathrm{P}<0.01)$. Pretreatment with 10-40 $\mu \mathrm{g} / \mathrm{ml} \mathrm{DHYZ}$ significantly inhibited the $A \beta_{25-35}$-induced caspase-3 activation in $\mathrm{PC} 12$ cells in a dose-dependent manner $(\mathrm{P}<0.01)$, and the effect of $40 \mu \mathrm{g} / \mathrm{ml}$ DHYZ in supressing caspase-3 activation was significantly greater than that observed for 10 and $20 \mu \mathrm{g} / \mathrm{ml}$ DHYZ $(\mathrm{P}<0.01)$.

Effect of DHYZ on A $\beta$-induced ROS generation in PC12 cells. A $\beta$-mediated ROS generation contributes to AD pathogenesis $(17,18)$. As shown in Fig. 7, exposure of PC12 cells to $A \beta_{25-35}$ for $24 \mathrm{~h}$ significantly increased ROS generation as compared with the control cells $(\mathrm{P}<0.01)$. Pretreatment with 20 


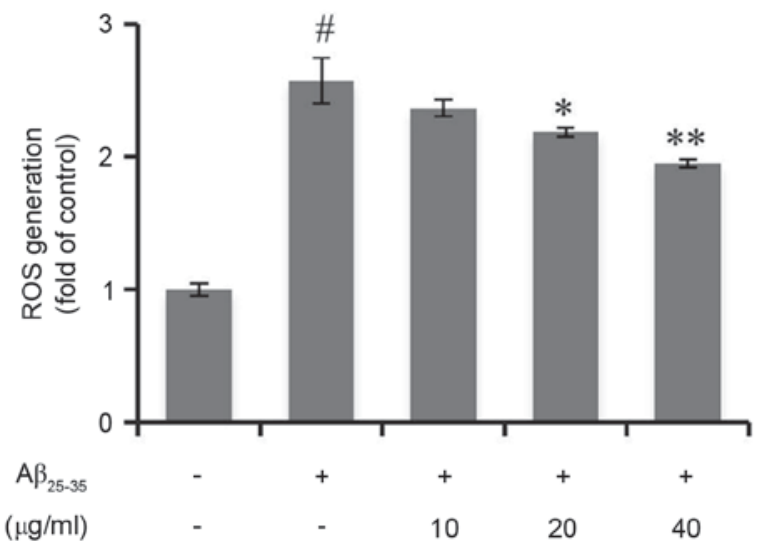

Figure 7. Effect of DHYZ on $\mathrm{A} \beta_{25-35}$-induced ROS generation in PC12 cells. Differentiated PC12 cells were pretreated with different concentrations of DHYZ for $1 \mathrm{~h}$, followed by A $\beta 25-35$ treatment for $24 \mathrm{~h}$. The production of intracellular ROS was detected by DCFH-DA staining and quantified with a fluorescence microplate reader (excitation wavelength, $488 \mathrm{~nm}$; emission wavelength, $525 \mathrm{~nm}$ ). ROS production was expressed as the fold of the control group. Data shown are representative of three independent experiments. ${ }^{~} \mathrm{P}<0.01$ vs. non-treated group; ${ }^{*} \mathrm{P}<0.05$ and ${ }^{* *} \mathrm{P}<0.01$, vs. $\mathrm{A} \beta_{25-35}$ group DHYZ, Di-Huang-Yi-Zhi; A $\beta$, amyloid- $\beta$; ROS, reactive oxygen species; DCFH-DA, 2',7'-dichlorofluorescin diacetate.

and $40 \mu \mathrm{g} / \mathrm{ml}$ of DHYZ significantly reduced the ROS production $(\mathrm{P}<0.05)$, and the effect of $40 \mu \mathrm{g} / \mathrm{ml} \mathrm{DHYZ} \mathrm{in} \mathrm{reducing}$ ROS was significantly greater than that observed for 10 and $20 \mu \mathrm{g} / \mathrm{ml}$ DHYZ $(\mathrm{P}<0.05)$. Collectively, these observations suggest that DHYZ exerts neuroprotective effects against $A \beta$-induced neurotoxicity, which may contribute to the therapeutic effects of DHYZ in the treatment of AD.

\section{Discussion}

According to TCM theory and clinical observations, the pathogenesis of AD is closely associated with kidney deficiency resulting in brain malnutrition, blood stasis and phlegm retention $(7,19)$. In the DHYZ formula, Shu-Di is used as a Monarch (Jun) herb for nourishing the kidney. The Dan-Shen and Shi-Chang-Pu in the DHYZ formula are used as Minister (Chen) for dissolving stasis and phlegm, and calming the mental state. Fu-Shen is used as an Assistant (Zuo) herb to calm the nerves, while Yi-Zhi-Ren is used as a Guide (Shi) herb to warm the kidney.

Certain herbs in the DHYZ formula have been demonstrated to be beneficial in AD. Shu-Di is one of the most frequently used herbs for AD treatment, and has been shown to improve learning and memorizing ability in aluminum chloride-induced dementia mice (20). Shu-Di can also inhibit p53, p21 and p16 expression, protect brain tissue from oxidation and delay brain senescence in D-galactose-induced senile rats $(21,22)$. Catalpol, a compound in Shu-Di, has been demonstrated to attenuate the $\mathrm{A} \beta_{1-42}$-mediated neurotoxicity, improve the endocrine function and alleviate structural damage of the hypothalamus in $\mathrm{A} \beta_{25-35}$-induced $\mathrm{AD}$ rats $(23,24)$.

Dan-Shen inhibits acetylcholinesterase and protects PC12 cells from A $\beta$-induced cytotoxicity (25). In addition, Shi-Chang-Pu protects $\mathrm{PC} 12$ cells from $\mathrm{A} \beta_{25-35}$-induced cell damage, mitochondrial dysfunction, ROS generation and cell death (26). Yi-Zhi-Ren has been demonstrated to have protective effects on learning and memory impairments, neuronal damage and apoptosis induced by $\mathrm{A} \beta_{1-42}(27) .5$-Hydroxymethylfurfural, a compound isolated from Yi-Zhi-Ren, ameliorates learning and memory impairment, inhibits $\beta$-secretase activity, increases antioxidative enzyme activities and mitigates neuronal damage in $\mathrm{A} \beta_{1-42}$-induced AD mice (28).

Extracellular amyloid plaques have been identified as one of the pathological characteristics in the AD brain, and amyloid-mediated neuron damage is a major cause of AD (29). In the present study, $A \beta_{25-35}$ was found to significantly reduce cell viability and increase $\mathrm{LDH}$ release due to membrane damage, which confirmed the neurotoxicity of $\mathrm{A} \beta_{25-35}$ on neuronal differentiated PC12 cells. DHYZ pretreatment significantly reversed these changes induced by $A \beta_{25-35}$, suggesting that DHYZ has neuroprotective effects against $\mathrm{A} \beta_{25-35}$-mediated toxicity and may be beneficial for AD treatment.

$A \beta$ induces mitochondrial dysfunction leading to the release of $\mathrm{Cyt}-\mathrm{C}$, which forms an apoptosome and activates the initiating protease caspase-9, which in turn activates the executioner caspases-3, and ultimately results in apoptosis $(30,31)$. In the present study, $A \beta_{25-35}$ treatment downregulated the MMP, increased the mitochondrial $\mathrm{Cyt}-\mathrm{C}$ release and activated caspase- 3 accompanied by apoptosis induction in PC12 cells. Pretreatment with DHYZ inhibited these changes, suggesting that DHYZ protected PC12 cells from $\mathrm{A} \beta_{25-35}$-induced apoptosis.

The A $\beta$ peptide may also increase ROS generation (32). A high level of ROS promotes cell death via the mitochondrial pathway and/or death receptor pathway (33). Components in the DHYZ formula, such as catalpolcatalpol, tanshinone IIA and Shi-Chang-Pu extract, may inhibit $\mathrm{A} \beta$-induced ROS generation $(26,34,35)$. In the present study, DHYZ pretreatment was observed to attenuate the $\mathrm{A} \beta$-induced ROS production in PC12 cells, suggesting that ROS inhibition may contribute to DHYZ-mediated neuroprotective effects.

In conclusion, the present study demonstrated that DHYZ exerted neuroprotective effects against $\mathrm{A} \beta_{25-35}$-mediated neurotoxicity by alleviating $A \beta_{25-35}$-induced proliferation inhibition, apoptosis and ROS generation. The present study provides new insight into the application of Chinese herbs for $\mathrm{AD}$ treatment that are worthy of further investigation.

\section{Acknowledgements}

The present study was supported by grants from the National Natural Science Foundation of China (no. 81470195), the Research Project from Shanghai Municipal Health and Family Planning Commission (no. 2014XZ005A), the Three-year Action Program of Shanghai Municipality for Traditional Chinese Medicine (no. ZY3-JSFC-2-2003), and the Opening Research Fund of Shanghai Key Laboratory of Tissue Engineering (no. TE1401).

\section{References}

1. Masters CL and Selkoe DJ: Biochemistry of amyloid $\beta$-protein and amyloid deposits in Alzheimer disease. Cold Spring Harb Perspect Med 2: a006262, 2012.

2. Butterfield DA, Swomley AM and Sultana R: Amyloid $\beta$-peptide (1-42)-induced oxidative stress in Alzheimer disease: Importance in disease pathogenesis and progression. Antioxid Redox Signal 19: 823-835, 2013. 
3. Tayeb HO, Yang HD, Price BH and Tarazi FI: Pharmacotherapies for Alzheimer's disease: Beyond cholinesterase inhibitors. Pharmacol Ther 134: 8-25, 2012.

4. Yu L, Lin SM, Zhou RQ, Tang WJ, Huang PX, Dong Y, Wang J, $\mathrm{Yu} \mathrm{ZH}$, Chen JL, Wei L, et al: Chinese herbal medicine for patients with mild to moderate Alzheimer disease based on syndrome differentiation: A randomized controlled trial. Zhong Xi Yi Jie He Xue Bao 10: 766-776, 2012 (In Chinese).

5. Zhang YX, Zhang YL and Lu Y: Systematic review of randomized controlled trials of traditional Chinese medicine in treating Alzheimer's disease. Chin J Trad Chin Med Pharm 27: 105-109, 2012.

6. Liang JF, Guo JW, Fu B and Liu Y: Clinical efficacy of combined Chinese and western medicine in treatment of Alzheimer disease: A meta-analysis. J Shanxi Med Univ 45: 209-212, 2014

7. An HM, Jin M, Hu B, Chen JL, Yu ZH and Gu C: Effects of Dihuang-Yi-Zhi-Fang on learning and memory ability in senile dementia rats induce by A $\beta 1-40$. Chin J Gerontol 32: 1409-1411, 2012 (In Chinese).

8. Gu C, Yuan CX, Shen T, Ye Q, Liu T and An HM: A clinical observation on Dihuang Yizhi Formula combined with Donepezil for 50 patients with Alzheimer's disease. J Trad Chin Med 55: 482-485, 2014.

9. Lin GB, Xie Y, Li GW, An HM and Yuan XR: Extraction and inclusion process of mixed volatile oil in Dihuang Yizhi granules. Chin J Exp Trad Med Formul 17: 32-35, 2011.

10. Lin GB, Xie Y, Li GW, An HM and Yuan XR: The aqueous extract and purification technique of Dihuang Yizhi granules Chin Trad Patent Med 34: 1385-1387, 2012.

11. Lin GB, Xie Y, Li GW and An HM: Studies on quality standard of Dihuang Yizhi granules. Chin J Trad Chin Med Pharm 27: 2785-2788, 2012

12. Park SY, Kim HS, Cho EK, Kwon BY, Phark S, Hwang KW and Sul D: Curcumin protected PC12 cells against beta-amyloid-induced toxicity through the inhibition of oxidative damage and tau hyperphosphorylation. Food Chem Toxicol 46: 2881-2887, 2008.

13. Xing G, Dong M, Li X, Zou Y, Fan L, Wang X, Cai D, Li C, Zhou L, Liu J and Niu Y: Neuroprotective effects of puerarin against beta-amyloid-induced neurotoxicity in PC12 cells via a PI3K-dependent signaling pathway. Brain Res Bull 85: 212-218, 2011.

14. Kumar S, Seal CJ, Howes MJ, Kite GC and Okello EJ: In vitro protective effects of Withania somnifera (L.) Dunal root extract against hydrogen peroxide and $\beta$-amyloid(1-42)-induced cytotoxicity in differentiated PC12 cells. Phytother Res 24: 1567-1574, 2010.

15. Favaloro B, Allocati N, Graziano V, Di Ilio C and De Laurenzi V: Role of apoptosis in disease. Aging (Albany NY) 4: 330-349, 2012.

16. Meier P and Vousden KH: Lucifer's labyrinth-ten years of path finding in cell death. Mol Cell 28: 746-754, 2007.

17. Pagani L and Eckert A: Amyloid-Beta interaction with mitochondria. Int J Alzheimers Dis 2011: 925050, 2011.

18. Dumont M and Beal MF: Neuroprotective strategies involving ROS in Alzheimer disease. Free Radic Biol Med 51: 1014-1026, 2011.

19. Peng JH, Mei XY and Zhang TY: TCM pathogenesis and syndrome differentiation research progress of senile dementia. J Nanjing Univ Trad Chin Med (Natural Science) 27: 598-600, 2011 (In Chinese).
20. Shen YH, Cao YJ, Cui Y and Hou SL: Effects and mechanism of prepared Radix Rehmanniae on memory in dementia mice. Shanghai J Trad Chin Med 41: 67-68, 2007.

21. An HM, Shi YF, Hu B, Shi XF, Zhang ZP, Xu LW, et al: Prepared Radix Rehmanniae delay brain senescence in D-galactose induced senile rats. Pharm Clin Chin Mater Med 24: 59-60, 2008.

22. An HM, Shi YF, Hu B, Shi XF, Zhang ZP, Xu LW and Gu MC: Effects of Prepared Radix Rehmanniae on brain cell cycle and related gene expression. Chin Pharm 11: 1145-1147, 2008.

23. Jiang B, Du J, Liu JH, Bao YM and An LJ: Catalpol attenuates the neurotoxicity induced by beta-amyloid(1-42) in cortical neuron-glia cultures. Brain Res 1188: 139-147, 2008.

24. Wang JH, Li WT, Yu ST, Xie H and Han HR: Catalpol regulates function of hypothalamic-pituitary-adrenocortical-axis in an Alzheimer's disease rat model. Pharmazie 69: 688-693, 2014

25. Zhou Y, Li W, Xu L and Chen L: In Salvia miltiorrhiza, phenolic acids possess protective properties against amyloid $\beta$-induced cytotoxicity, and tanshinones act as acetylcholinesterase inhibitors. Environ Toxicol Pharmacol 31: 443-452, 2011.

26. An HM, Li GW, Lin C, Gu C, Jin M, Sun WX, Qiu MF and $\mathrm{Hu}$ B: Acorus tatarinowii Schott extract protects PC12 cells from amyloid-beta induced neurotoxicity. Pharmazie 69: 391-395, 2014.

27. Shi SH, Zhao X, Liu AJ, Liu B, Li H, Wu B, Bi KS and Jia Y: Protective effect of n-butanol extract from Alpinia oxyphylla on learning and memory impairments. Physiol Behav 139: 13-20, 2015.

28. Liu A, Zhao X, Li H, Liu Z, Liu B, Mao X, Guo L, Bi K and Jia Y: 5-Hydroxymethylfurfural, an antioxidant agent from Alpinia oxyphylla Miq. Improves cognitive impairment in $A \beta 1-42$ mouse model of Alzheimer's disease. Int Immunopharmacol 23: 719-725, 2014.

29. Bloom GS: Amyloid- $\beta$ and tau: The trigger and bullet in Alzheimer disease pathogenesis. JAMA Neurol 71: 505-508, 2014.

30. Yankner BA and Lu T: Amyloid beta-protein toxicity and the pathogenesis of Alzheimer disease. J Biol Chem 284: 4755-4759, 2009.

31. Wang X, Su B, Perry G, Smith MA and Zhu X: Insights into amyloid-beta-induced mitochondrial dysfunction in Alzheimer disease. Free Radic Biol Med 43: 1569-1573, 2007.

32. Viña J, Lloret A, Giraldo E, Badia MC and Alonso MD: Antioxidant pathways in Alzheimer's disease: Possibilities of intervention. Curr Pharm Des 17: 3861-3864, 2011.

33. Circu ML and Aw TY: Reactive oxygen species, cellular redox systems, and apoptosis. Free Radic Biol Med 48: 749-762, 2010.

34. Liang JH, Du J, Xu LD, Jiang T, Hao S, Bi J and Jiang B: Catalpol protects primary cultured cortical neurons induced by Abeta (1-42) through a mitochondrial-dependent caspase pathway. Neurochem Int 55: 741-746, 2009.

35. Liu T, Jin H, Sun QR, Xu JH and Hu HT: The neuroprotective effects of tanshinone IIA on $\beta$-amyloid-induced toxicity in rat cortical neurons. Neuropharmacology 59: 595-604, 2010. 